\title{
Os pais da psicanálise com crianças*1
}

Adela Stoppel de Gueller*2

Durante meio século, a história da psicanálise com crianças guiou-se pelas linhas mestras estabelecidas no Colóquio sobre análise infantil, que em 1927 entronou Melanie Klein e Anna Freud como suas genuínas mães. Um dos efeitos que se produziram foi a psicanálise com crianças se haver consagrado como um campo de mulheres. Contudo, anteriores a essas mulheres, estão os que podemos considerar os pais da psicanálise com crianças - mas que não foram reconhecidos como tais. Entre eles, Karl Abraham, Carl Jung e Max Graf. O que se esconde nesse apagamento? Que efeitos isso teve na prática psicanalítica com crianças? O artigo levanta a hipótese de que a fantasia do pai sedutor dissuadiu os homens de se aventurarem nesse campo.

Palavras-chave: História da Psicanálise com crianças, psicanalistas homens, Sigmund Freud e Carl Jung, Karl Abraham, Max Graf

${ }^{* 1} \mathrm{O}$ trabalho faz parte de projeto de pós-doutoramento "Escritas da clínica psicanalítica com crianças: história e transmissão da experiência", desenvolvido na Universidade Estadual do Rio de Janeiro, sob supervisão de Ana Costa e com subsídio da Capes.

Uma versão preliminar foi apresentada oralmente no III Colóquio de Psicanálise com Crianças: Onde Está o Pai, realizado no Instituto Sedes Sapientiae, em São Paulo, nos dias 10 e 11 de outubro de 2014.

*2 Universidade Estadual do Rio de Janeiro - UERJ (Rio de Janeiro, RJ, Br). 
Por que a prática clínica com crianças é prioritariamente conduzida por mulheres? É consenso no meio analítico que Melanie Klein e Anna Freud são as mães da psicanálise com crianças. Mas será que ela também tem pais? Tenho encontrado ricas experiências de análises com crianças conduzidas por analistas homens, todas anteriores a 1927, ou seja, anteriores ao Colóquio sobre análise infantil, data situada como nascimento oficial dessa prática. Por que essas experiências foram recalcadas? O que se esconde na pré-história da psicanálise com crianças?

Vários analistas de peso se aventuraram nesse terreno, mas não constam como pioneiros. Entre eles, Sándor Ferenczi e Karl Abraham, os dois analistas de Melanie Klein, Moshe Wulff e Carl Jung e, evidentemente, Max Graf.

Desses tempos primordiais, sobreviveu um único vestígio: o pequeno Hans, uma das cinco grandes psicanálises de Sigmund Freud. Contudo, o fato de esse caso constar assim na obra de Freud parece manter o recalque sobre o lugar do analista da criança - seu pai.

Max Graf conhecia Freud pelos relatos que Olga Hönig fazia dele como sua paciente, sob transferência. ${ }^{1}$ Foi então conhecer o professor e perguntar se considerava Olga em condições de contrair matrimônio. Freud lhes deu sua benção, e eles casaram. Mais tarde, Max foi vê-lo novamente para contar que a vida sexual do casal não ia bem. Freud o aconselhou a ter um filho, e desse conselho nasceu Herbert, o pequeno Hans.

No texto de 1909, Freud se refere a Max como "o pai", "um próximo aderido", "um aluno", "um analista iniciante". Mas, como

${ }^{1} \mathrm{O}$ tratamento de Olga Hönig transcorreu em 1897, quando ela contava 19 anos. Freud o menciona em 22 de junho desse ano, numa carta a Wilhelm Fliess, a quem diz que sua jovem paciente perdera o pai aos 11 meses de vida e sofria de "ideias obsessivas quase puras" (Eissler, 2008). 


\section{ARTIGO}

diz Martine Gauthron (1992), o trabalho de transcrição de Freud deixa na penumbra a versão de Max Graf sobre a análise de seu filho. Por que Freud opta por esse velamento? Por que se deixou na sombra a incidência que a presença real do pai teve na condução do tratamento $?^{2}$

Os poucos elementos destacados por Freud sobre o lugar do pai de Hans eram que ele reunia (Vereinung) a autoridade paterna e a médica numa pessoa só e aliava (Zusammentreffen) o interesse afetivo ao interesse científico. Segundo Freud, isso constituía Max no único Outro da palavra possível para levar adiante a análise com uma criança. Hans só poderia confiar e colocar no lugar de suposto saber seu pai. Essa afirmação engendrou longas controvérsias sobre se a criança era capaz de estabelecer transferência com alguém que não fosse sua mãe ou seu pai em função de sua neurose ser atual, ou seja, de ela não se haver ainda desligado dos vínculos originários.

Contudo, Geissmann \& Geissmann (1998) apontam que, mesmo antes de o caso Hans ser publicado, Freud já afirmava que a criança era capaz de estabelecer transferência. Em 13 de maio de 1907, Jung escreveu a Freud: "Tenho em tratamento analítico, no momento, uma menina de seis anos com masturbação excessiva e mentiras, que alega ter sido seduzida pelo pai. A coisa é bem complicada. Você tem experiência com crianças?" (Freud, 1993, pp. 24-25). Os mesmos autores acreditam que essa tenha sido uma provocação, posto que Jung sabia perfeitamente que Freud ainda não se aventurara nesse terreno, e pensam ainda que essa carta tenha apressado a publicação do pequeno Hans.

Jung disse que ensaiou a hipnose com essa menina porque a ab-reação e a sugestão não tinham dado resultado. A partir do que escutou [na hipnose], perguntou a Freud: "De onde a criança conhece todas as histórias sexuais?". Jung diz que, na primeira sessão, ela alucinou espontaneamente "uma salsichinha para assar, que a mulher dizia que ficava cada vez mais grossa". Ele

${ }^{2}$ Em entrevista a K. Eissler (2008), disse Max Graf: "Meu filho, que tinha nesse momento quatro anos, desenvolveu uma fobia, uma angústia na presença de cavalos. Era impossível tirá-lo do apartamento porque temia os cavalos. Tive então que usar a psicanálise com ele. Quero dizer, em minhas conversações, quando ele contava seus sonhos e sem que tivesse que deitar-se num divã, sem que pudesse compreendê-lo. A cada dia, registrava isso imediatamente e assim explorei eu mesmo esse material para descer um pouco mais longe no inconsciente. Quando lhe contei, Freud me disse que era muito importante dar-lhe o que havia registrado a cada noite, depois das conversações com a criança, não é verdade? Procedi com esse tratamento psicanalítico adaptando-o a uma criança, até o momento em que o sintoma da angústia da fobia aos cavalos desapareceu". 
então lhe perguntou onde via a salsicha, e ela disse "sobre M., o doutor!". (Geissmann \& Geissmann, 1998, p. 25).

Podemos então aventar a hipótese de que os textos "O esclarecimento sexual da criança" (publicado em junho de 1907) e "Sobre as teorias sexuais infantis" (1908) tentam dar respostas à questão levantada por Jung. Freud ainda respondeu, na carta 23 de maio de 1907: "o fato de que a criança não fala provém daquilo que se coloca inteiramente e plenamente na transferência, como sua observação mostra" (Geissmann \& Geissmann, 1998, p. 25).

Chama atenção que, embora Freud ainda pensasse a transferência como uma resistência, não duvidava da capacidade da criança de deslocar para a figura do médico o lugar da autoridade e do saber. Ele então parece precisar justificar que a análise de Hans fosse conduzida pelo pai, talvez porque ainda não estivesse muito convencido da aplicação da psicanálise a crianças.

$\mathrm{O}$ fato é que Jung não quis ficar para trás na pesquisa desse novo campo da psicanálise, e apresentou, junto a Freud, na Clark University, o caso Aninha. Tratava-se da análise de sua filha mais velha, Ágata, que nesse momento tinha quatro anos. ${ }^{3}$

Vale a pena destacar que esse é o primeiro caso, de uma série, em que 228 se esconde que o pai é o analista da criança. Jung diz: "Recebi de certo pai, entendido em psicanálise, uma série de observações a respeito de sua filhinha de quatro anos" (Jung, 1964a, p. 13). Em 1919, Melanie Klein adotou um procedimento semelhante, apresentando o caso Fritz como o do filho de uns vizinhos.

Temos até aqui um pai deixado na sombra pelo pai da psicanálise e um pai escondido atrás de "certo pai". Freud é o pai que vela pela psicanálise. Max Graf é o pai velado por trás de Freud. Jung é o pai que não se revela.

Que a história da psicanálise com crianças tenha tido início com a análise dos próprios filhos talvez não seja um dado conjuntural. Ao considerar essas histórias como erros de uma prática que dava seus primeiros passos, não fazemos mais do que voltar a recalcar. Agimos do mesmo modo quando, ao falar em análise de um sonho, dizemos "ah! isso não é importante". A proximidade do incestuoso que emerge nesses relatos incomoda, logo, não é casual que essas experiências fundantes tenham caído no mais profundo esquecimento. Acreditamos que elas evocam o fantasma fundamental que essa prática

${ }^{3} \mathrm{O}$ trabalho foi publicado com o nome de "Conflitos da alma infantil". 


\section{ARTIGO}

suporta, na medida em que o incesto é aquilo que precisa ser recalcado. Isso não significa que nós, analistas, devamos instaurar como baluartes da resistência nem que repitamos sem querer relembrar. Isso bem pode ensurdecer nossa escuta e deixar-nos inoperantes ao receber uma criança e seus pais.

\section{Levantando o véu}

A propósito da publicação de Jung, em carta de 18 de agosto de 1910, Freud (1993) comenta:

Reli com prazer a fascinante história das crianças (Aninha e Sofia), lamentando, entretanto, que o pesquisador não dominasse o pai por completo; ela é de fato uma saliência delicada, quando poderia ter sido diamante bruto, e, devido a tal sutileza, a lição se perde para a maioria dos leitores. No medo de que o pai as queira afogar, percebe-se o simbolismo dos sonhos com água (mascaramento do nascimento). Pena que as analogias com o pequeno Hans não sejam devidamente trabalhadas, senão aqui e ali, pois o leitor é, por definição, um simplório, e é preciso que lhe esfreguemos as coisas no nariz. (p. 362; grifo nosso)

Embora pouco antes Jung (1910/1964b) tivesse escrito "Importância do pai no destino dos filhos", Freud queria um destaque para o lugar do pai que Jung não deu ao analisar sua filha - sua preocupação maior fora dar sustentação à existência das teorias sexuais infantis. O tom da crítica de Freud sugere que a questão do pai o tocava diretamente. Em outra carta, de 25 de janeiro de 1909, ele escreve a Jung:

(...) decerto o senhor distingue (no caso Aninha) as principais facetas do caso Hans. Tudo aí não poderia ser típico? Tenho muita fé num complexo nuclear das neuroses que dá origem às duas resistências básicas: o medo do pai e a descrença nos adultos, ambas integralmente transferíveis para o analista. (Freud, 1993, p. 227)

Freud tinha razão em apontar as semelhanças entre Ágata e Herbert Graf. Ambos os casos começaram como observações e só depois se tornaram tratamentos, em função do surgimento de sintomas fóbicos. Terá sido justamente essa observação tão atenta e minuciosa que propiciou o surgimento das fobias? Seriam as fobias uma resposta do sujeito para velar o olhar do pai?

No início, Ágata faz perguntas sobre a sexualidade e a morte à mãe e à avó. Ela temia perder o amor da mãe pelo nascimento de um irmãozinho e não 
sabia com quem devia se identificar: com a mãe ou com a ama que dava de mamar ao bebê? E insistia em perguntar se a mãe mentia para ela. É da mãe, e não do pai, que ela desconfia. Nesse momento, surge uma fobia de terremotos. Tinha havido um terremoto em Messina, na Itália, com 75 mil mortos, e Ágata pedia que a avó lhe contasse como a terra tinha tremido, como tinham caído as casas, como milhares de pessoas haviam morrido soterradas. Ela começa a ter medo de ficar só. Se a mãe não ficava ao lado de sua cama, à noite, dizia que "o terremoto viria e a casa cairia, matando-a". Quando saía de casa, perguntava: "A casa vai estar inteira quando voltarmos? Papai ainda vai estar vivo? Tem certeza de que lá em casa não tem terremoto?".

Ágata acordava gritando: "O terremoto está chegando! Ouço o rugido dele!". Esse curioso substantivo dá uma pista para pensar que o terremoto é como um leão, logo, poderia ser um substituto da figura paterna, se supusermos uma operação semelhante à que Freud inferiu com o cavalo de Hans. Assim como o cavalo, o terremoto é uma figura ameaçadora, temida. Mas o traço que Aninha extrai dessa figura é o rugido que remete à voz do pai. Não é, como o cavalo, uma boca que morde e pode arrancar uma parte preciosa do corpo, mas um rugido que faz perder o chão. Jung não faz essa inferência, e esse parece ter sido o motivo da crítica de Freud. Nesse pequeno fragmento do caso, temos os dois elementos apontados por Freud como constituintes do complexo nuclear das neuroses e que reaparecerão na transferência como resistência à análise: o medo do pai e a descrença nos adultos. Mas também devemos nos contrapor a Freud em certa medida. A fobia de Ágata surge em função de sua desconfiança da palavra da mãe. É a mãe-terra-que-treme e a deixa desprotegida frente à avalanche de questões que a sexualidade e a morte lhe suscitam.

Tal como Hans, Ágata não queria sair de casa, temia perder o pai, o terremoto podia separá-los para sempre. Que seria dela sem o pai? Que garantia tinha de que voltaria e o encontraria vivo? De que nenhuma fenda na terra a impediria de retornar? ${ }^{4}$

Após a análise de Ágata, Jung decide não mais analisar crianças, tarefa que passa a delegar a mulheres. No primeiro Congresso Internacional de Pediatria, realizado em 1911 em Bruxelas, disse:

${ }^{4} \mathrm{O}$ simbolismo do terremoto, contudo, também remete à mãe. É digno de nota que Ágata começa a ficar angustiada quando suspeita que sua mãe mente. É a palavra do adulto que fica $s u b$ judice, e, assim, a menina perde o solo que a sustenta. 


\section{ARTIGO}

Algumas análises são mais bem conduzidas por mulheres. Venho formando algumas mulheres para tratar psicanaliticamente de crianças. Parece que, para as mulheres, essa será uma nova profissão. Tenho passado as análises de crianças a uma de minhas assistentes, ${ }^{5}$ e, depois de bastante experiência, cheguei à conclusão de que as mulheres, por sua intuição psicológica natural, são muito mais aptas para realizar essa tarefa. (Jung, $1912^{6}$ apud Geissmann \& Geissmann, 1998, p. 32)

A pergunta que fica silenciada é: o que desautoriza os homens a analisarem crianças? A fala de Jung naturaliza a nova profissão como adequada a mulheres, mas deixa na sombra os motivos que o dissuadiram de conduzir esses tratamentos.

\section{O diário da análise de Hilda Abraham}

Outro dos casos esquecidos na história da psicanálise com crianças é a análise que Abraham fez com sua filha mais velha, Hilda. Abraham escreveu "Pequena Hilda: fantasias e sintoma em uma menina de sete anos de idade" em 1913, mas não o publicou. O texto que tem a forma de um diário, ficou guardado a sete chaves até que em 1974 foi publicado na International Review of Psycho-Analysis, com notas de Dinora Pines, psicanalista da British Society, amiga de Hilda.

O sintoma de Hilda era falta de atenção, e Abraham começou a analisá-la em função de uma queixa da professora. Hilda era inteligente, e a desatenção desaparecia quando ela se interessava por algo, como uma história que lhe contassem. Um dia, saíram para andar e Abraham the explicou que, como médico, realmente gostaria de saber o que estava havendo com ela, por que ela nunca prestava atenção na escola, continuamente devaneava em casa e ficava acordada muito tempo à noite. Ela disse que se esforçava para ter pensamentos agradáveis na escola, mas então vinham pensamentos feios e proibidos que se misturavam. Disse que tinha três fantasias recorrentes, mas, tentando falar delas, nomeou apenas duas. A primeira fantasia dizia

${ }^{5}$ Jung se refere a Maria Moltzer (1874-1944).

${ }^{6}$ Jung, C. (1912). Congress Report, Brussels, 1912, v. II, p. 332-343. 
respeito a macacos, como se houvesse um alçapão no chão de seu quarto e, embaixo dele, houvesse macacos que lhe pudessem fazer algo. A segunda se referia a uma chama fogosa que poderia sair do chão. De repente, ela se lembrou que também pensava em gigantes, mas sabia que eles só existiam nos contos de fadas. Então, apelando para sua autoridade de médico, o pai lhe disse: "Já ouvi muitas vezes falar em sonhos de crianças em que um cachorro despertou ansiedade, mas, na verdade, o cachorro representava uma pessoa". ${ }^{7}$ Imediatamente, ela entendeu que, na verdade, estava com medo de homens, que, em suas fantasias, havia transformado em gigantes. Dois dias depois, ela trocou a palavra "gigantes" por "homens maus" e disse que um ladrão poderia entrar em casa e lhe fazer algo. Poderia levá-la com ele para ver sua esposa, poderia "querer ter uma criança", poderia deixá-la morrer de fome. Se o ladrão a levasse embora, não seria possível voltar para casa novamente. Aí, falou do macaco que poderia devorá-la. Abraham comentou que, enquanto ela contava a história do ladrão, seu comportamento mudou estranhamente:

Ela pegou meu braço, beijou a manga do meu casaco, enroscou a cabeça perto de mim e foi tão amorosa e terna, em palavras e olhares, que eu tive a impressão de que havia aspectos positivos em sua ansiedade a respeito do homem mordaz e assumi que eu mesmo devo ser um deles. (Abraham, 1913/1974, p. 13)

Ela então quis falar da chama e disse que também poderia levá-la embora. Depois, me perguntou se eu já havia escutado de outras pessoas algo parecido e como as havia ajudado. Eu disse que as pessoas se sentiam melhor quando falavam de seus pensamentos com o médico e que, à noite, podiam se deitar em paz na cama. Ela perguntou: "Eles te consultam com mais frequência, não é?". Pouco tempo depois, Hilda falou dos macacos que poderiam mordê-la, que um rato poderia pular da cabeceira para sua cama, rastejar por baixo dos lençóis e mordiscá-la, do homem mau que poderia vir e pegá-la. Ele a deixaria morrer de fome ou a morderia, ou a levaria a um policial e lhe contaria que ela havia feito algo mau, e assim ele a colocaria na prisão. Abraham então falou a Hilda sobre a autocensura das crianças e lhe explicou sua conexão com a masturbação, que ela confessou.

${ }^{7}$ Abraham provavelmente se refere ao caso descrito por Wulff (1912). 


\section{ARTIGO}

O diário guardado em segredo falava da fantasia de sedução da menina por seu pai. Aos sete anos, Hilda se excita e tem medo do pai. As fantasias de ser roubada, de morrer de fome, de ser mordida ou ser sequestrada falam de seus desejos eróticos transformados em masoquísticos, por influência do sentimento de culpa decorrente da incorporação do pai que se tornou voz do supereu. Reencontrava-se assim o fantasma que tinha dado origem à psicanálise ${ }^{8} \mathrm{O}$ fato de o pai da realidade estar na posição de analista situava a sedução como uma cena real ou fantasiada? Realidade psíquica ou realidade material ou histórica? Freud sempre disse "Non liquet". "Essa diferença que outros ${ }^{9}$ consideram fundamental, essa diferença não é essencial (...). As crianças traduzem (umsetzen) esses impulsos em atos. E é disso que falam as teorias sexuais infantis" (Le Gaufey, 2002, p. 31).

Se a menina nutre fantasias eróticas em relação ao pai, pode esse pai ou um homem - ser seu analista? Não alimentaria o pai — ou um analista homem - ainda mais essa produção? Nesse mesmo ano, Freud escreve "Totem e tabu", texto que instaura a proibição do incesto como universal e decorrente do pai morto ou, nos termos de Lacan, do pai simbólico. Então, reformulando a mesma questão, o fato de o pai ser o analista impediria o assassinato do pai? Impediria o pai de tornar-se guardião da proibição do incesto? Ou, ao contrário, seria a análise de crianças um tempo/lugar que possibilitaria o assassinato do pai propiciando assim a transformação do pai imaginário em pai simbólico? (Le Gaufey, 2002, p. 34).

Seja para salvar o pai real de ser assassinado ou para possibilitar livrar-se da prisão que o pai imaginário perpetua, a proibição de ter um analista homem se aplicaria às meninas; mas o que pensar dos meninos?

\footnotetext{
${ }^{8}$ Abraham voltaria a falar dessa fantasia num pequeno texto publicado em 1917, "Algumas ilustrações sobre a relação afetiva de meninas pequenas para com seus pais", em que apresenta os casos Elsie e Hellen, que contavam quatro anos, centrando-se em manifestações de desejo de morte da mãe e sentimentos eróticos em relação ao pai expressos sem inibição. Dinora Pines, na apresentação do diário, diz que uma das meninas seria Hilda. Nós acreditamos que se trata de Hellen, mas Abraham não revela a fonte do material.

${ }^{9}$ Le Gaufey (2002, p. 31) assinala: “outros [der Anderem] é Jung”.
} 


\section{Pai, não corras de mim}

Sigamos nosso questionamento tomando um pequeno fragmento do caso Hans: um diálogo entre ele e seu pai, três dias depois da visita a Freud. O pai pergunta ao menino por que foi à cama dos pais:

Hans: Quando não tiver medo, não virei mais.

Pai: Então, você vem para junto de mim porque está assustado?

Hans: Quando não estou assustado, eu fico assustado; quando não estou na cama junto com você, fico assustado. Quando eu não estiver mais, assustado eu não venho mais.

Pai: Então, você gosta de mim e se sente aflito quando está na sua cama, de manhã? E por isso é que você vem para junto de mim?

Hans: Sim, por que é que você me diz que eu gosto da mamãe, quando eu gosto é de você?. (Freud, 1909/1996c, p. 38)

Freud vê a cilada em que Hans se encontra e diz que essa é a causa da angústia: "O pai não compreende tudo, pois durante esse diálogo só compreende a hostilidade do pequeno para com ele, que eu tinha afirmado em nossa consulta" (Freud, 1909/1996c, p. 38). Ou seja, Max insiste em sublinhar a versão positiva e normatizante do complexo de Édipo, sem no entanto ver que a angústia é causada pela indecisão quanto à escolha objetal.

$\mathrm{Na}$ sequência, Hans fala do temor de que seu pai não volte para casa dizendo: "Pai não 'corras' (davonrennen) de mim". O pai se interroga sobre essa expressão, que indicaria o temor de que fuja, e replica: "Você teme que o cavalo corra de você?" - e Hans ri. Em seguida, Freud fala da angústia perante o pai e da angústia pelo pai: "a primeira provém da hostilidade ao pai, a segunda, do conflito entre a ternura, exagerada aqui pela via da reação e da hostilidade" (p. 39). A interpretação de Freud assinala o aspecto reativo do exagerado amor de Hans pelo pai, cuja finalidade seria mascarar a ambivalência dos sentimentos. Tal interpretação deixa na sombra a identificação do menino com a mãe e seus desejos eróticos em relação ao pai.

\section{Os pais analistas}

Lacan distinguiu três registros - e não dois, como Freud. Em Freud, há o pai da realidade e o pai da fantasia. Em Lacan, há o pai real, o simbólico e o imaginário. O pai simbólico é o pai morto, eternizado pela 


\section{ARTIGO}

culpa dos filhos; é aquele que proíbe gozar com a mãe. Só o pai morto consegue ser guardião/vigia da lei. Só seu nome talhado no túmulo é garantia da proibição do incesto.

O pai imaginário é o pai edipiano por excelência. Ele tem duas faces: como pai terrífico, é uma versão masculina da mãe onipotente que impede gozar com a mãe; como figura protetora, é como um irmão mais velho. É um herói, mas também é excessivamente libidinoso.

O pai real surge sempre como um mau encontro (tiqué) entre o pai e o filho. Nesse momento, puramente contingente, uma fenda se abre entre ambos. Esse instante transformador tem consequências decisivas na constituição subjetiva da criança, já que possibilita a transformação do pai imaginário em simbólico. Trata-se então do instante em que se assassina o pai, ou o que poderíamos designar também como o momento do despertar do sonho; por isso Le Gaufey (2002) o denomina "morto-pai" (distinguindo-o do pai-morto), o que assinala esse momento transformador que adquire dimensão de acontecimento, ou seja, que separa o antes do depois. Assim, o pai real é o guardião do sonho que fica dormido, deixando a criança pegar fogo. "Pai, não vês que estou queimando?" - grita o filho e o faz despertar.

Quando o filho - menina ou menino - corre em direção ao pai para tocar nele o ponto vivo da paternidade, o pai como causa no processo de filiação, acontece correntemente de ele ou ela malograrem, e esse malogro é o assassinato do pai. Não, portanto, sei lá que agressividade de rivalidade edipiana - em que nossos modernos psicólogos se apressam em ver um "assassinato simbólico" que emanciparia a criança da tutela paterna -, mas um encontro fracassado, algo que não advém e que, a esse título, produz uma espécie de estrago inteiramente essencial no processo da subjetividade. (Le Gaufey, 2002, p. 33)

Nossa hipótese é que o encontro entre pai e analista alimentava fantasias eróticas em relação ao pai tanto em meninas quanto em meninos e, afastando os homens da análise com crianças, tentava-se evitar a erupção fogosa dessas fantasias que fragilizavam o pai. Em outros termos, evitava-se seu assassinato.

Para o filho, o pai real frequentemente encontra figurabilidade no filho desejado que o pai não dá, doravante denominado falo imaginário, já que, por mais generoso, disponível e provedor que seja, isso o pai não dá, o que acaba ocasionando o encontro faltoso necessário. Por esse motivo, Lacan afirma que o agente da operação simbólica da castração é o pai real, aquele que deve ser morto (Lacan, 1957/1994). 
Trabalhamos com três desses primeiros casos da pré-história da psicanálise com crianças. Os pontos comuns entre eles são que as três crianças foram analisadas por seus pais e os três casos são ricos em fantasias e teorias sexuais próprias desse período da vida. $\mathrm{O}$ que ficou sepultado junto com essas histórias: a sexualidade perversa polimorfa? Esses tempos primordiais ficaram recalcados para salvar o pai? Se assim for, que pai teria ficado sepultado: o real? Chama atenção que os primeiros tempos da psicanálise com crianças pareçam precisar de recalque, de modo análogo à sexualidade infantil. Mas, se a psicanálise já adquiriu maturidade suficiente, talvez seja a hora de levantar o véu para não precisar repetir eternamente.

\section{Epílogo}

Em 1908, ano em que Freud escrevia sobre as teorias sexuais infantis e Jung fazia seus primeiros ensaios com crianças, do outro lado do canal da Mancha, mais precisamente em Londres, trabalhando no West End Hospital, Ernest Jones atendeu uma menina de dez anos que sofria de paralisia histérica. Depois desse atendimento, ela contou "a outras crianças que o doutor lhe havia falado sobre temas sexuais". Resumo da ópera: Jones foi acusado pelos pais da menina de pedofilia e teve que renunciar a seu cargo. Realidade ou fantasia infantil? Também aí Freud responderia "non liquet". Acreditamos que essa cena representa a realização do fantasma mais temido da psicanálise com crianças e que dissuadiu os analistas homens de se aventurarem nesse campo. Nesses termos, podemos concluir que, mais do que salvar o pai, tratava-se de pôr um véu sobre a verdade intragável que o polimorfismo perverso da infância tinha implantado desde os "Três ensaios...", cujo correlato é o pai sedutor. Mas, agindo dessa forma, não estaria a própria psicanálise recalcando sua maior descoberta? (Rodrigué, 1996, p. 199).

Nesse sentido, a psicanálise com crianças parece ser um campo sempre fértil para fazer germinarem resistências à psicanálise e na própria psicanálise, ou seja, uma espécie de doença autoimune. Ela porta a peste que Freud implantou. Afastar os pais, permitir que educadores - e não médicos - a exerçam ou amenizar as falas das crianças por meio do jogo podem pôr um véu que é necessário, mas não conseguirão eliminar a peste que ficou incorporada à psicanálise de crianças desde sua origem (Derrida, 1997, p. 10). 


\section{ARTIGO}

Agradeço a cuidadosa leitura e as críticas de Ana Costa e Ricardo Goldemberg e a Fabiana Bigio e Ana Beatriz Albernaz, pelo valioso trabalho de tradução do diário de Karl Abraham.

\section{Referências}

Abraham, K. (1917). Some illustrations on the emotional relationship of little girls towards their parents. In Abraham, K., Clinical Papers and Essays on Psycho-analysis. Manufactured on the United States of America. p. 52-54. Recuperado em 27 dez. 2014 de: <http://books.google.com.br/books?id=XFNrLPjAty8C\&lp$\mathrm{g}=\mathrm{PA} 52 \&$ ots $=7-\mathrm{P} 3 \mathrm{~h} 2 \mathrm{cqFw} \& \mathrm{dq}=\mathrm{karl} \% 20 \mathrm{Abraham} \% 201917 \% 20$ some $\% 20$ illustrations $\% 20$ on $\% 20$ the $\% 20$ emotional\%20relationship $\% 20$ of $\% 201$ ittle $\% 20$ girls $\% 20$ to $\% 20$ the $\% 20$ parents \&hl $=$ pt-BR\&pg $=\mathrm{PA} 53 \# \mathrm{v}=$ onepage $\& \mathrm{q}=\mathrm{karl} \% 20 \mathrm{Abraham} \% 20$ $1917 \% 20$ some $\% 20$ illustrations $\% 20$ on $\% 20$ the $\% 20$ emotional\%20relationship $\% 20$ of $\% 20$ little $\% 20$ girls $\% 20$ to $\% 20$ the $\% 20$ parents\&f=false $>$.

Abraham, K. (1974). Little Hilda: Daydreams and a Symptom in a Seven Years Old Girl. International Review of Psycho-Analysis, 1, 5-14. (Trabalho original publicado em 1913).

Derrida, J. (1997). Resistencias del psicoanálisis. Buenos Aires: Paidós.

Eissler, K. (2008). Reportaje a Max Graf realizado por Kurt Eissler (16 de diciembre 1952). Fort-Da-Revista de Psicoanálisis con Niños, 10, noviembre. Recuperado em 27 dez. 2014 de: <http://www.fort-da.org/fort-da10/repomaxgraf.htm>.

Freud, E.; Abraham, H. (1993). A correspondência completa de Sigmund Freud e Carl G. Jung. Rio de Janeiro: Imago.

Freud, S. (1996a). Tres ensayos de teoría sexual. In Obras Completas (v. VII). Buenos Aires: Amorrortu. (Trabalho original publicado em 1905).

Freud, S. (1996b). El delirio y los sueños en la 'Gradiva' de Jensen. In Obras Completas (v. XIII). Buenos Aires: Amorrortu. (Trabalho original publicado em 1907).

Freud, S. (1996c). Análisis de la fobia de un niño de cinco años (el pequeño Hans). In Obras Completas (v. X). Buenos Aires: Amorrortu. (Trabalho original publicado em 1909).

Freud, S. (1996d). Cinco conferencias sobre psicoanálisis. In Obras Completas (v. XI). Buenos Aires: Amorrortu. (Trabalho original publicado em 1910).

Freud, S. (1996e). Tótem y tabú. In Obras Completas (v. XIII). Buenos Aires: Amorrortu. (Trabalho original publicado em 1913).

Freud, S.; Abraham, K. (2001). Correspondencia Completa Sigmund Freud-Karl Abraham 1907-1926. Madrid: Síntesis. 
Gauthron, M. (1992). Max Graf, go-between entre Freud e Hans. Littoral, 34/35, 151-158.

Geissmann, C.; Geissmann, P. (1998). A History of Child Psychoanalysis. London: The New Library of Psychoanalysis.

Graf, M. (2014, janeiro). Reminiscencias del profesor Sigmund Freud (1942). El Psicoanalista Lector. Recuperado em 27 dez. 2014 em: <http://elpsicoanalistalector. blogspot.com.br/2014/01/max-graf-reminiscencias-del-profesor.html>.

Hug-Hellmuth, H. (1975). Journal d'une petite fille. Paris: Seuil. (Trabalho original publicado em 1928).

Jung, C. (1964a). Conflictos del alma infantil. Buenos Aires: Paidós.

Jung, C (1964b). Importancia del padre en el destino de sus hijos. In Conflictos del alma infantil (pp. 68-87). Buenos Aires: Paidós. (Trabalho original publicado em 1910).

Lacan, J. (1994). El seminario. Libro IV. La relación de objeto. Buenos Aires: Paidós. (Trabalho original publicado em 1957).

Le Gaufey, G. (2002). Pai, então não vês que estou queimando? In J. Moingt et al., Littoral: do Pai (pp. 29-36). Rio de Janeiro: Cia. de Freud.

Rodrigué, E. (1996). Sigmund Freud: el siglo del psicoanálisis. Buenos Aires: Sudamericana.

Wulff, M. (1912). Beitrage zur infantilen Sexualitat. Zentralblatt für Psychoanalyse, $2,6-17$.

\section{Resumos}

(The fathers of child psychoanalysis)

For half a century, the history of child psychoanalysis was based on guidelines established by the Symposium on Child Analysis, which, in 1927, enthroned Melanie Klein and Anna Freud as its genuine mothers. One of the results produced was child psychoanalysis being consecrated as a field for women. However, before these women, there are those who we can consider the fathers of child psychoanalysis but who were never recognized as such: among them, Karl Abraham, Carl Jung and Max Graf. What lies below this erasure? What effects did this have on child psychoanalysis practice? This paper raises the hypothesis that the seductive father fantasy dissuaded men from venturing into this field.

Key words: History of child psychoanalysis, male psychoanalysts, Sigmund Freud and Carl Jung, Karl Abraham, Max Graf 


\section{ARTIGO}

(Les pères de la psychanalyse avec les enfants)

Pendant un demi-siècle, l'histoire de la psychanalyse avec les enfants a été guidée par les lignes directrices énoncées dans le Colloque sur l'analyse des enfants, qui, en 1927, définit Mélanie Klein et Anna Freud comme ses véritables mères. L'une des conséquences a été la consécration de la psychanalyse avec les enfants comme un domaine réservé aux femmes. Toutefois, derrière ces femmes, il y a ceux que nous pouvons considérer comme les pères de la psychanalyse avec les enfants - mais qui n'ont pas été reconnus comme tels: parmi eux, Karl Abraham, Carl Jung et Max Graf. Que se cache-t-il derrière cet effacement? Quels ont été les effets sur la pratique psychanalytique avec les enfants? L'article soulève l'hypothèse que le fantasme du père séducteur a dissuadé les hommes de s'aventurer dans ce domaine.

Mots clés: Histoire de la psychanalyse avec les enfants, psychanalystes hommes, Sigmund Freud et Carl Jung, Karl Abraham, Max Graf

(Los padres del psicoanálisis con niños)

Durante medio siglo, la historia del psicoanálisis con niños se pautó por los lineamientos que se establecieron en el Coloquio sobre el análisis de niños que, en 1927, entronizó Melanie Klein y Anna Freud como sus madres genuinas. Uno de los efectos que se produjeron fue que el psicoanálisis con niños se consagró como un campo de mujeres. Sin embargo, hay detrás de ellas aquellos que podemos considerar sus padres, que no fueron reconocidos como progenitores: entre ellos están Abraham, Jung y Max Graf. ¿Qué se esconde detrás de esa desaparición? ¿Qué efectos tubo sobre la práctica psicoanalítica con niños? El artículo levanta la hipótesis de que la fantasía del padre seductor alejó a los hombres a aventurarse en ese campo.

Palabras clave: Historia del psicoanálisis con niños, psicoanalistas hombres, Sigmund Freud y Carl Jung, Karl Abraham, Max Graf

(Die Väter der Kinderpsychoanalyse)

Während eines halben Jahrhunderts entwickelte sich die Geschichte der Kinderpsychoanalyse anhand von Richtlinien, die sich aus dem Kolloquium über Kinderpsychoanalyse ergaben, welches im Jahr 1927 Melanie Klein und Anna Freud als die wahren Mütter der Kinderpsychoanalyse prägte. Als Folge etablierte sich die Kinderpsychoanalyse als ein Berufsfeld für Frauen. Hinter diesen Frauen ahnen wir jedoch diejenigen, die wir als Väter betrachten können, unter ihnen Abraham, Jung und Max Graf. Was führte dazu, dass sie in den Hintergrund traten? Wie wirkte sich dies auf die angewandte Kinderpsychoanalyse aus? Dieser Artikel stellt die Hypothese auf, dass die Phantasie des verführerischen Vaters die Männer davon abgehalten hat, sich in dieses Feld zu wagen.

Schlüsselwörter: Geschichte der Kinderpsychoanalyse, männliche Psychoanalytiker, Sigmund Freud und Carl Jung, Karl Abraham, Max Graf

Rev. Latinoam. Psicopat. Fund., São Paulo, 19(2), 225-241, jun. 2016 


\section{(儿童精神分析学之父)}

在半个世纪的时空, 儿童精神分析学的历史由几条主要路线指引。这几条 路线在1927年由Melanie Klein和 Ana Freud提出, 这两位也就成为人们公认 的儿童精神分析学的创始人。由于这个原因, 儿童精神分析学成为一个以妇女 为主导的领域。但是, 在这两位女创始人之前, 实际上已经有好几位男性专 家关注了儿童精神分析学, 但是他们并没有被认为是这个领域的创始人。他们 是: Karl Abraham, Carl Jung 和 Max Graf。是什么原因使得人们忘记这几位 男性学者呢? 这又会对儿童精神分析这个行业造成什么影响呢? 本论文提出一 个假设, 也就是, 人们对父亲诱骗的幻觉使得男性精神分析专家不愿涉足儿童 精神分析学这个领域。

关键词：儿童精神分析学史, 男性精神分析家, 西格蒙德. 弗洛伊德, 卡尔. 荣格，卡尔·亚布拉罕，麦克斯·格拉夫。

Citação/Citation: Gueller, A. S. de. (2016, junho). Os pais da psicanálise com crianças Revista Latinoamericana de Psicopatologia Fundamental, 19(2), 225-241.

Editores do artigo/Editors: Prof. Dr. Manoel Tosta Berlinck e Profa. Dra. Sonia Leite

Recebido/Received: 11.3.2015/ 3.11.2015 Aceito/Accepted: 14.5.2015 / 5.14.2015

Copyright: (C) 2009 Associação Universitária de Pesquisa em Psicopatologia Fundamental/ University Association for Research in Fundamental Psychopathology. Este é um artigo de livre acesso, que permite uso irrestrito, distribuição e reprodução em qualquer meio, desde que o autor e a fonte sejam citados / This is an open-access article, which permits unrestricted use, distribution, and reproduction in any medium, provided the original authors and sources are credited.

Financiamento/Funding: Esta pesquisa foi financiada pela Coordenação de Aperfeiçoamento de Pessoal de Nível Superior - Capes-PNPD / The research was funded by the Coordenação de Aperfeiçoamento de Pessoal de Nível Superior - Capes-PNPD. 


\section{ARTIGO}

Conflito de interesses/Conflict of interest: A autora declara que não há conflito de interesses

/ The author has no conflict of interest to declare.

\section{Adela Stoppel de Gueller}

Psicanalista; Doutora em psicologia clínica pela Pontifícia Universidade Católica de São Paulo - PUC-SP (São Paulo, SP, Br); Pós-doutoranda pela Universidade do Estado do Rio de Janeiro - UERJ (Rio de Janeiro, RJ., Br); Professora do curso de especialização em Teoria Psicanalítica da COGEAE-PUC-SP e do curso de formação em Psicanálise da Criança do Instituto Sedes Sapientiae (São Paulo, SP, Br); Membro da Associação Universitária de Pesquisa em Psicopatologia Fundamental - AUPPF (São Paulo, SP, Br).

R. Dr. Homem de Melo, 736 - Perdizes

05007-002 São Paulo, SP, Br

adela@gueller.com.br

This is an open-access article, which permits unrestricted use, distribution, the original authors and sources are credited. 